\title{
How effective are the nutritional programs for schoolchildren in Romania?
}

\author{
Daniel Arpinte \\ Research Institute for Quality of Life \\ arpinte@gmail.com
}

DOI:10.5901/mjss.2014.v5n22p267

\begin{abstract}
The article assesses the analysis of the two European nutrition schemes in schools (milk and fruit) and how their implementation has contributed to the achievement of the specific objectives set for both programs, but also on the extent to which they can be used as support tools for children coming from poor families or for sustaining nutritional policies for schoolchildren. It provides a review of the evaluation reports of the European subsiding programs for nutrition in schools (The European schemes for milk and fruit and vegetables) in schools and uses the main findings of the last evaluation of the main Romanian nutritional programme (Role and milk). The article shows that the deficiencies identified for the European nutritional schemes are even pronounced at national level, mainly because of the lack of any strategically approach. The article ends with a proposal for an alternative for the development of a nutritional program adequate for better positioning within the scope of a strategy aiming at reducing the obesity and excessive weight.
\end{abstract}

Keywords: school food policy, nutritional policies, children obesity and excessive weight, socially disadvantaged children.

\section{Introduction}

The first measure targeting to provide a nutritional support for schoolchildren was implemented in Romania starting 2002 under the name "Role and Milk" (Corn și Lapte). The programs reach all children attending different forms of pre-university education, the European legislation including high-school education as eligible since 2008, while most Member States provide access to children in pre-school, primary or secondary (lower secondary) education, same as Romania, which excludes however from the program also some schools that offer alternative dining programs, such as extended-day program kindergartens. In 2009 a new component have been added by providing fresh fruits to pupils.

Although it has an enormous potential for supporting a nutritional policy targeting schoolchildren, the programme still lack in identity and strategically approach and is weakly consistent with the objectives of the European schemes that cofinancing the programme and provides a common framework of implementation at European level.

\section{Defining elements of the European nutritional schemes targeting schoolchildren}

The European schemes for milk and fruit in schools are two European programs with voluntary participation of the Member States, and receiving funding from the EU budget. Both schemes have similar objectives, aiming a) to support specific markets and contributing to the price stabilization for milk and milk by-products, namely fruit and vegetables and $b$ ) to increase the consumption of such products among children and youth by easier access to healthy food. Other significant changes made in 2008 are related to enhancing the educational component, more obviously in case of the fruit scheme, which since its inception has focused on the healthier nutritional behavior among children. Moreover, the fruit scheme explicitly stipulates mandatory implementation of educational activities, which still are not subsidized, being optional for the milk scheme. Another difference of the fruit scheme is that the products are distributed free of charge, the necessary budget differences for the procurement being borne by the participating states. The milk scheme allows free or low-cost distribution for the products.

\section{European School Milk Scheme}

The European School Milk Scheme is an EU program initiated in 1977 and aiming to support milk producers by encouraging milk consumption among children and young people and promoting a healthy diet. At first, the program focused on its 
primary objective, but its subsequent successive amendments emphasized the educational component. As a matter of fact, at European level, the impact of the program judging from the objective of stimulating milk market is negligible, the amount of milk distributed by the program being in average $0.3 \%$ of the total amount of milk produced in Europe (2013). In Romania, the program has the largest share from local market among the European countries, the program ensuring the acquisition of $5.4 \%$ of the total milk production. The budget for the 2011-2012 school year was of 90 million at European level. The subsidy is modest, covering between 10-15\% from the direct cost of the milk (Germany and UK) to $25 \%$ in Poland (2013), the differences being justified by the national prices.

The total number of children taking part in the program in Europe knows significant variations generated by the changes of the eligibility conditions within the states with a large number of school children (e.g. France, Italy, and Poland). From 21 million children in 2008-2009, the number of schoolchildren in the program dropped to 17.2 million in 2010-2011, and rising to 20 million in the 2011-2012 school year (2013). There is no limit for the subsidy coming from the EU budget, the amount of funding being conditioned only by the maximum number of children eligible for taking part in the program. At European level, $23 \%$ of the milk is distributed free of charge (for all eligible schoolchildren in Romania, primary schools in Poland), $33 \%$ at low price (Germany, secondary schools in Poland), and $44 \%$ is distributed in school cafeterias such as an added supplement for the served meals (France, Italy and Sweden).

The European Court of Auditors Report (2011) states that the scheme has a very limited impact. Initially it was estimated that, on short term, the school milk scheme will increase milk consumption among young people, and in the long run it will influence consumer behaviour (including among family members of the beneficiary schoolchildren). Both forms of impact were not confirmed by subsequent assessments $(1990,1999,20051,2011)$, in 1999 (1999) the termination of the program was even proposed due to negative conclusions on the impact and the achieved results. The recommendation of the evaluation report in 1999 was based on the fact that the impact of the program on the milk market was insignificant (the program representing $0.3 \%$ of the total milk consumption in the beneficiary countries); lowering the milk price, including in relation to other types of beverages (juices, mineral water) was not associated with an increase in consumption, but rather with a decrease; the program was not accompanied by educational measures promoting the consumption of milk and a healthy nutritional style. The European Court of Auditors Report (2011) notes some improvements from the time of the evaluation in 1999, but it shows that most deficiencies persist in varying degrees. The report also shows that the results are satisfactory only in the countries where milk is distributed free of charge.

\section{School Fruit Scheme}

The School Fruit Scheme was implemented starting with the 2009-2010 school year having an annual budget of 90 million in Europe, with different national funding corresponding to the degree of development of the component regions, $75 \%$ being allocated to the convergence regions and $50 \%$ for the rest of the regions. The co-financing is provided by the Member States so that products are distributed free of charge to children. Unlike the milk scheme, the Member States are obliged to implement accompanying measures in order to ensure children and young people knowledge about healthy eating and the importance of fruit and vegetables consumption.

The impact on the fruit and vegetable market is much lower as for the milk scheme, the produced consumption rising to $0.06 \%$ ( 5 times lower than for the milk scheme). Within the 2010-2011 school year the scheme had 8.15 million beneficiary children, representing $25 \%$ of the total of eligible children for the program (2012). But the program is in its early stage of implementation, the absorption degree at European level of the available budget (90 million) being of $61.6 \%$ for the 20112012 school year. The national co-financing was approximately 40\%, much lower compared to the milk scheme, although there are funds allocated for accompanying measures aiming education, which are estimated at $4.5 \%$ of the total amount spent on implementing the scheme. Romania has one of the lowest acquisition costs for the fruits distributed in schools, but the efficiency is also a result of the sporadic distribution. In countries where there is a higher frequency for the distribution of goods (3-5 times per week) the price significantly increases due to the higher share of logistics costs (transport, storage). Some of the deficiencies of the school milk scheme at European level were taken in consideration for the fruit scheme, leading to positive results in implementation, as shown by the results of an evaluation in 2012 ((2012). The main change occurred in managing the educational component, compulsory for the fruits and vegetable scheme which allow a better impact on promoting a healthy eating behaviour.

\footnotetext{
1 The evaluation is 2005 was accomplished only in UK
} 


\section{The implementation of the European schemes in Romania}

The "Role and Milk" Program runs under Law 6/2012 amending and supplementing the Government Emergency Ordinance 96/2002 on providing dairy and bakery products for schoolchildren between the 1st and the 8th grade in both private and public education system, and also preschool children in private and public kindergartens with 4 hours normal program. At first, the program reached children in primary and secondary school, and was expanded in 2009 also to early school education. The initial maximum limit was of 0.7 RON (about 0, 15 Euro) amended in 2008 up to 1.17 RON (0, 26 Euro), which should have covered both the bakery and the dairy products. While the 2002 and 2009 the law was allowing limited distribution of milk-based products (up to $33 \%$ of the maximum quantity), from 2012 the milk by-product is restricted to yogurt, distributed under the same maximum limit. This is a restriction that the European Commission does not impose, the distribution of by-products being possible under certain conditions concerning the content of milk or individualizing the product. Another restriction, but which reflects the intention to streamline the management of the program, refers to the accountability of the coordination within the county councils, respectively local councils for Bucharest's sectors. The funding of the program is also in charge of these institutions.

From the total grant covered by the EU, Romania is being allocated 12\% (for the 2011-2012 school year), the received amount being of 8.29 million euros and partly covering the costs on dairy products distributed to children. The contribution of the Member States is voluntary and focuses on the quality or the quantity of products children receive. For Romania, in addition to the co-financing for dairy products, the national contribution also consists in bakery products, distributed along with the first ones. According to the dimension of the grant received from the EU budget, Romania demands one of the largest amounts (in absolute terms) together with Poland, France and Sweden, although it has a considerably smaller target group (school population covered by the program).

Romania reports the highest consumption per schoolchild, along with Sweden, Finland and Denmark. While in Romania the number of eligible school aged children for joining the program is of 1.95 million, in Poland it reaches 6.55 million and in France 13.59 million. By contrast, when speaking about the general population, Romania has, along with Bulgaria, the lowest amount of the annual milk consumption per-capita: almost 20 times less than Finland or Ireland, the countries with the highest consumption in Europe (about $140 \mathrm{~kg}$ per capita, annual average for the period 2000-2010). In what concerns cheese consumption reported to the same period, Romania ranks last among the EU27, with an annual consumption of about $5 \mathrm{~kg}$ per-capita, nearly 10 times less than in the countries with the highest consumption (Denmark, France, Italy).

Also for the fruit and vegetables scheme, Romania has about $12.7 \%$ of the beneficiary children within the participating states, after Spain with $12.9 \%$ and Italy with $16.5 \%$ (2012). For fruits, the maximum cost is lower than for the "Role and milk" program, the maximum amount reaching $0.37 \mathrm{RON} /$ day for each schoolchild. Data of the evaluation report for fruit and vegetables scheme (2012) shows that Romania had in 2010, along with Cyprus and Greece, one of the highest quantities of fruit and vegetables consumed per capita. However, the daily consumption in Romania has the most significant decrease comparing to 2006 (almost $30 \%$ ). Also, a particularity in Romania is the high rate of rural population ensuring their agricultural needs in their own household, so it is likely that the high share of fruits and vegetables consumption isn't the result of a modern nutritional style but that of practicing the subsistence agriculture with a high share of self-consumption in the total consumption.

Romania does not show any discordance at European level regarding the impact of the two schemes, the results being modest. A particularity should be mentioned, however. Although the trend in other European countries is for the program to position itself as one of encouraging healthy eating, in Romania it is rather perceived as the main support tool for poor children, although it has no strategic direction defined, other than the opportunity of accessing European resources, when talking about public policies. Therefore, the implementation is rather focused on logistical and administrative aspects and ignores the schoolchildren as main beneficiaries and their nutritional needs. However, one of the main source of inefficiency is in serving the products and the lack of adjustment / diversification to the requirements of the schoolchildren (Arpinte et al., 2009). However, the same evaluation showed that the "Roll and milk" program (implicitly the fruit scheme introduced after) is significant for children coming from poor families, especially for those whom their families cannot provide the nourishment need. Surprisingly, among with children from poor families, the poor children in rural areas represent a significant category for which the program means a main source of food, although is commonly known that in rural area even the poorest families are able to cover their minimal feeding needs.

Even if the program proves to be helpful for poor schoolchildren, periodically the policy makers propose different alternatives for changing the program, the main reason being the lack of interest of most schoolchildren (except the poor ones) for the distributed products. The assessment report (Arpinte et al., 2009) shows that only a small proportion of the schoolchildren consume the dairy and bakery products, mostly because of their poor quality. 
Policy options for the effective implementation of the two European schemes

Despite the deficiencies analysed above, some of them being common for the most participating countries, while other are specific at national level, the schemes have some incontestable advantages:

They are supported with EU subsidies - although the received funds from EU budget are not significant (for role and milk programme the subsidies cover about $20 \%$ of the cost of programme, but the share in the cost of the milk, the subsidized product, is even higher). By stopping the participation into the programmes are lost important resources for supporting a nutritional programme in schools regardless the way of the implementation (in current formula or developed as a more complex nutritional programme).

The schemes have an important awareness component, more emphasised for fruits and vegetables scheme, which might be further used as a tool for various nutritional awareness activities in schools that are deficient in the Romanian educational system.

They are supporting the milk and fruits markets, aspects that are more important in case of Romania than for other participating countries. If at European level the average of the milk used for the school scheme is about $0.3 \%$ from total market, in Romania represents about $5.4 \%$.

However, implementing the programme in current formula (providing the products free of charge and addressing all eligible schoolchildren allowed) should be changed at strategically approach level. As explained above, the implementation of the schemes in Romania lacks in vision that negatively impact on final beneficiaries. From addressing schoolchildren belonging to poor families, the scheme are useful but inefficient considering that they addresses all school children, most of them not consuming the products. Therefore, the opportunity of using the schemes as a tool for promoting a healthy lifestyle and reducing the obesity is lost.

\section{Alternatives for the development of an effective nutritional policy in schools}

The importance of a school food policy targeting all children, and including adequate measures for including pupils belonging to socially vulnerable groups is demonstrated by various evaluations. Such programs have both a positive impact on improving the nutritional intakes of the all participating children and reducing the inequalities in diet for children from different social backgrounds (Adamson et al., 2012, $\underline{\text { He, 2012, Hinrichs, 2010). }}$.

Considering the actual needs, a possible alternative of nutritional policy for schoolchildren should be focused on:

Addressing all schoolchildren by promoting a healthy lifestyle through improving the existing schemes subsidized by EU funds (milk in schools and fruit and vegetables)

Developing an additional system for meals in schools addressing all schoolchildren, but free of charge only for children belonging to families with low incomes.

\section{Addressing all schoolchildren by promoting a healthy lifestyle}

An important category for the two nutritional schemes might be represented by children at risk of nutritional diet imbalance (mainly because of consumption of high calorie, but nutrient poor food products), their number increasing rapidly during the last years.

Data coming from WHO Initiative of child obesity surveillance in Europe for the 2007-2008 school year show that the prevalence of overweight (including obesity) among children aged 6 to 9 years included ranges between 19 and $49 \%$ in boys and 18 and $43 \%$ in girls within the 13 European countries where data were collected, Malta having the highest share, and Netherlands the lowest (Wiinhoven et al., 2013). WHO Initiative has expanded to the subsequent school years, with Romania part of the third wave (the 2012-2013 school year), the data being not yet available.

Although the common perception of poverty is associated with the lack of food, so children's access to European schemes would supplement such poor nutritional supply, a number of studies (Branca et al., 2007, Low, 2010) show that obesity affects in a higher weight the poor, reducing their chances of social reintegration. In fact, WHO estimates that $75 \%$ of overweight or obese children will come from small and medium-income countries, where malnutrition will continue to affect a significant proportion of children (Low, 2010). The objectives of the two schemes are related to the European strategy for 
nutrition, overweight, obesity and health related problems1, showing that most of the health problems are associated with a poor, unbalanced diet. At European level, in 2007 it was estimated (Branca et al., 2007) that 22 million children are overweight (20\%) of whom 5.1 million are obese (data don't include Bulgaria and Romania). WHO shows that the obesity prevalence is 10 times higher than in the '70s, and the projections for 2010 were showing almost three times increase in the number of obese children ( 15 million) (Branca et al., 2007). The effects of obesity are being felt on long-term. Overweight or obese children aged 3 to 8 years already have vascular lesions and are at risk of being victims of bullying or social isolation (McBride, 2010, Low, 2010). Other authors show that there is a double risk for obese children than for the normal weight children to deal with overweight as adults (Oude Luttikhuis et al., 2009).

The concerns of the public institutions for population's nutrition and diet, especially children's, are not enough clearly outlined in order to confirm the priority of the domain and the importance of the nutritional imbalances (malnutrition or obesity) problem and related health risks. An initiative is the Plan of action on food and nutrition developed by the National Food and Nutrition Committee, a document which is actually a draft of a potential strategy. The document recognizes the importance of nutrition and child feed, focusing on early age. The "Roll and milk" program is mentioned as a measure within the course of action aiming to reduce deficiencies of calcium, vitamin $A$, vitamin $D$, vitamin $B$ complex. The brief legislative framework is represented by four pieces of legislation that regulate hygiene rules within the institutions for the care, education and training of children and youth (Order 1955 from October 18, 1995), the establishment of the National Food and Nutrition Committee (Order 687 from March 27, 2008), the list of un-recommended food products for children and teenagers and of the principles underlying on their healthy nutrition (Order 1563 from 2008) and healthy eating in preuniversity education schools (Law 123 from 2008). Thus, except for the order 1563 from 2008, which stipulates a set of rules on child nutrition and lists food types that can't be sold or distributed in pre-university education schools, the legislation proves to be poor and insufficient for the regulation of a strategy on nutrition and food for children and teenagers. A major difficulty for a detailed strategic plan, addressed in a realistic manner, is the lack of data on diet habits and the prevalence of obesity in children.

Some measures for sustaining the strategic option should be considered:

increasing the role of school in choosing dairy products or fruits to distribute schoolchildren. This way, a better response to consumer preferences of schoolchildren is provided.

Assuring a flexible integration into complementary programs implemented in school.

differentiated approach depending on children's age (e.g., increasing the attractiveness of the packaging or content for younger children and in accordance with their consumption habits).

reviewing the approach of the nutritional supplement based on the latest recommendations coming from the nutritionists

Developing an additional system for meals in schools addressing all schoolchildren, but free of charge or provided at reduced price only for poor children

The most common proposals coming from the teachers (Arpinte et al., 2009) for reviewing the program aimed at improvement by providing the nutritional supplement exclusively to poor schoolchildren. Such option is budgetary affordable in the context of scarcity of the resources for the development of new social programs, but has a series of disadvantages, the most important ones being the difficulty of implementing the test meaning system for selecting the poor children and exposing the beneficiaries to potential prejudices. In this context, the most suitable solution is to provide a meal for all children, but free of charge or at a reduced price for children belonging to vulnerable groups. The main advantage for such option is that may became the main pillar for the nutritional policy targeting the children. However, the access differentiated, free of charge or at a reduced price for vulnerable pupils, is the most common practice in the other European countries. Excepting the Sweden and Finland, where the meal is provided free of charge for all schoolchildren, in the other countries (UK, France, Spain, Italy) where a meal in provided in schools, only poor pupils are entitled to receive the meal free of charge or at a reduced price (Clare Harper et al., 2008). For instance, in Italy the meal price is reduced by $25 \%$ for the children belonging to the families with low income (10.643 euro annually) or free of charge for families with incomes lower than 3.537 euro. Such differentiated system would eliminate some disadvantages associated to the alternative designed only for the poor pupils that may expose them to the risk of discrimination and prejudices. Also, it will keep the advantages for supporting further policies aiming at reducing obesity and weight excess among schoolchildren and promoting a healthy lifestyle. 


\section{References}

1999. Evaluation of the school milk measure. Final report. DGVI European Commision.

2011. Are the school milk and school fruit schemes effective? : European Court of Auditors.

2012. Evaluation of the European School Fruit Scheme. Final report. AFC Management Consulting AG.

2013. Evaluation of the EU School Milk Programme. European Commision.

ADAMSON , A., WHITE, M., STEAD, M., SPENCE, S., DELVE, J., STAMP, E., MATTHEWS, J. \& EADIE, D. 2012. The process and impact of change in the school food policy on food and nutrient intake of children aged 4-7 and 11-12 years both in and out of school; a mixed methods approach. Public Health Research Consortium.

ARPINTE, D., CACE, S., PREOTESI, M. \& TOMESCU, C. 2009. Cornul ș̣ laptele : percepții, atitudini și eficiență [Role and milk: perceptions, attitudes and efficiency) , Bucureșii, Editura Expert.

BRANCA, F., NIKOGOSIAN, H. \& LOBSTEIN, T. 2007. The challenge of obesity in the WHO European Region and the strategies for response: summary, World Health Organization.

CLARE HARPER, WOOD, L. \& MITCHELL, C. 2008. The provision of school food in 18 countries.

HE, C. 2012. Assessment of the impact of organic school meals to improve the school food environment and children's awareness of healthy eating habits. PhD dissertation, Aalborg University.

HINRICHS, P. 2010. The effects of the National School Lunch Program on education and health. Journal of Policy Analysis and Management, 29, 479-505.

LOW, L. K. 2010. Childhood obesity in developing countries. World Journal of Pediatrics, 6, 197-199.

MCBRIDE, D. 2010. Childhood obesity. Practice Nurse.

OUDE LUTTIKHUIS, H., BAUR, L., JANSEN, H., SHREWSBURY, V. A., O'MALLEY, C., STOLK, R. P. \& SUMMERBELL, C. D. 2009. Interventions for treating obesity in children. Cochrane Database Syst Rev, 1.

WIJNHOVEN, T. M. A., VAN RAAIJ, J. M. A., SPINELLI, A., RITO, A. I., HOVENGEN, R., KUNESOVA, M., STARC, G., RUTTER, H., SJÖBERG, A., PETRAUSKIENE, A., O'DWYER, U., PETROVA, S., FARRUGIA SANT'ANGELO, V., WAUTERS, M., YNGVE, A., RUBANA, I. M. \& BREDA, J. 2013. WHO European Childhood Obesity Surveillance Initiative 2008: weight, height and body mass index in 6-9-year-old children. Pediatric Obesity, 8, 79-97. 